\title{
Erratum to: Nanoscale zero-valent iron flakes for groundwater treatment
}

\author{
R. Köber' ${ }^{1}$ H. Hollert ${ }^{2}$ - G. Hornbruch ${ }^{1}$ - M. Jekel ${ }^{3}$ - A. Kamptner ${ }^{4}$. \\ N. Klaas ${ }^{5}$ - H. Maes ${ }^{2}$ - K.-M. Mangold ${ }^{6}$ - E. Martac ${ }^{7}$ - A. Matheis ${ }^{5}$. \\ H. Paar ${ }^{3}$ A. Schäffer ${ }^{2}$ H. Schell ${ }^{8}$ A. Schiwy ${ }^{2}$ K. R. Schmidt ${ }^{8}$. \\ T. J. Strutz ${ }^{1} \cdot$ S. Thümmler ${ }^{4}$ A. Tiehm ${ }^{8} \cdot$ J. Braun $^{5}$
}

Published online: 21 March 2016

(C) Springer-Verlag Berlin Heidelberg 2016

\section{Erratum to: Environ Earth Sci (2014) \\ 72:3339-3352 \\ DOI 10.1007/s12665-014-3239-0}

The original article has been published inadvertently with some errors. Corrected and supporting information is given below.

$25 \mathrm{~mL}$ of $6 \mathrm{mM}$ sodium boron hydride $\left(\mathrm{NaBH}_{4}\right)$ was used for the investigations of coatings.
The start concentration of iopromide solutions for the reactivity comparison of different particle batches was $2 \mathrm{~g} /$ $\mathrm{L}(2.5 \mathrm{mmol} / \mathrm{L})$.

$725 \mathrm{mg}$ PCE were used for the longterm reactivity column test with the particle production batch B2.

Equation 1 should be replaced by the following equation:

$\frac{\partial\left(n C_{i}\right)}{\partial t}+\sum_{i} \rho_{b} \frac{\partial\left(S_{i}\right)}{\partial t}=-\nabla\left(v_{f} C_{i}\right)+\nabla\left(n D_{i} \nabla C_{i}\right)$

The online version of the original article can be found under doi:10.1007/s12665-014-3239-0.

R. Köber

rk@gpi.uni-kiel.de

1 Institute for Geosciences, Christian-Albrechts-University of Kiel (CAU), Olshausenstr. 40, 24098 Kiel, Germany

2 Institute for Environmental Research (Biology 5), RWTH Aachen University, Worringerweg 1, 52074 Aachen, Germany

3 Technical University of Berlin, Str. des 17. Juni, 10623 Berlin, Germany

4 UVR-FIA GmbH, Chemnitzer Straße 40, 09599 Freiberg, Germany

5 VEGAS-Research Facility for Subsurface Remediation, University of Stuttgart, Pfaffenwaldring 61, 70569 Stuttgart, Germany

6 DECHEMA-Forschungsinstitut, Theodor-Heuss-Allee 25, 60486 Frankfurt, Germany

7 Fugro Consult GmbH, Volkmaroder Straße 8c, 38104 Braunschweig, Germany

8 Department of Environmental Biotechnology, TZW-Water Technology Center, Karlsruher Straße 84, 76139 Karlsruhe, Germany 
Figure 1 should be replaced by the following graph:

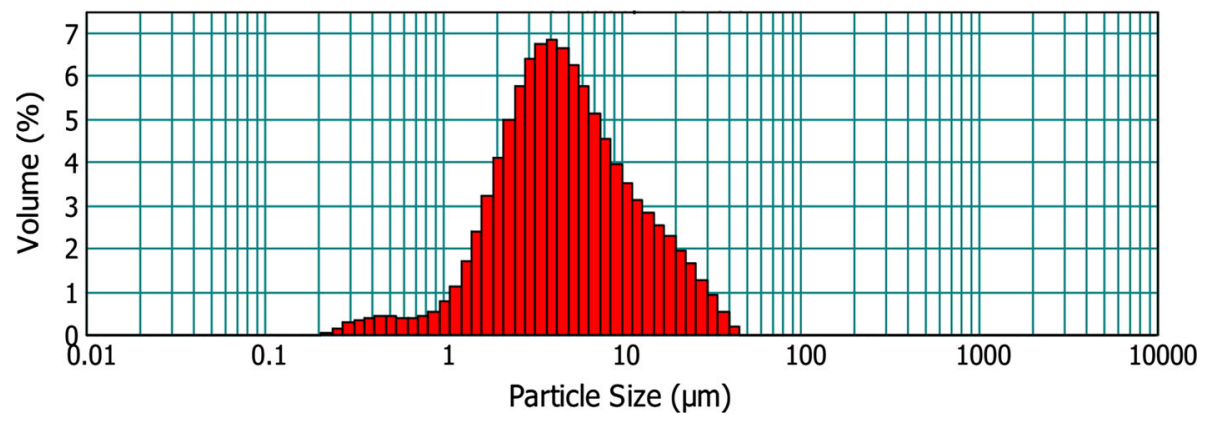

Caption of Table 2: Observed first-order rate constants $\left(K_{\text {obs }}\right)$ and used $\mathrm{Fe}(0)$ masses for the batch tests shown in Fig. 3.

$K_{\text {obs }}$ for B1 in Table 2: $3.02 \times 10^{-3} \mathrm{~s}^{-1}, R^{2}=0.99$.

The produced mass of TCE was $13.5 \mathrm{mg}$ instead of $2.8 \mathrm{mg}$.

Decimal and digit grouping symbols were not used consistently in some cases. Points followed by 000 were used as digit grouping symbols.
In the methodical section "Transport investigations" the batch notation B2 has to be replaced by B1 and on pp. 3347 and 3349 the notation B3 has to be replaced by B4.

The authors acknowledge Prof. Dr. Frank-Dieter Kopinke for his kind notes. 